\title{
The global ocean mass budget in 1993-2003 estimated from sea level change
}

\author{
Manfred Wenzel and Jens Schröter \\ Alfred Wegener Institute for Polar and Marine Research \\ Bussestrasse 24 \\ 27570 Bremerhaven \\ Germany
}

revised version:

January 27, 2006

Corresponding author :

Jens Schröter, Alfred-Wegener-Institute, Bussestr. 24, 27570 Bremerhaven, Germany. E-mail: jschroeter@awi-bremerhaven.de 


\begin{abstract}
The mass budget of the ocean in the period 1993-2003 is studied with a global circulation model. The model has a free surface and conserves mass rather than of volume, i.e. freshwater is exchanged with the atmosphere via precipitation and evaporation and inflow from land is taken into account. The mass is redistributed by the ocean circulation. Furthermore, the oceans volume changes by steric expansion with changing temperature and salinity. To estimate the mass changes the ocean model is constrained by sea level measurements from the TOPEX/Poseidon mission as well as by hydrographic data.

The modeled ocean mass change within the years 2002-2003 compares favourably well with measurements from the Gravity Recovery and Climate Experiment (GRACE) and the evolution of global mean sea level for the period 1993-2003 with annual and interannual variations can be reproduced to $0.15 \mathrm{~cm}$ RMS difference. Its trend has been measured as $3.37 \mathrm{~mm} /$ year while the constrained model gives $3.34 \mathrm{~mm} / \mathrm{year}$ concidering only the area covered by measurements $(3.25 \mathrm{~mm} / \mathrm{year}$ for the total ocean $)$. We estimate a steric rise of $2.50 \mathrm{~mm} /$ year in this period and a gain in the ocean mass which is equivalent to an eustatic rise of $0.74 \mathrm{~mm} / \mathrm{year}$. Amplitude and phase (day of maximum value since January 1) of the superimposed eustatic annual cycle are estimated. They are $4.6 \mathrm{~mm}$ and 278 degr., respectively. The corresponding values for the semiannual cycle are $0.42 \mathrm{~mm}$ and 120 degr. The trends in the eustatic sea level are not equally distributed. While in the Atlantic $(80 \mathrm{~S}-67 \mathrm{~N})$ the eustatic sea level rises by $1.8 \mathrm{~mm} /$ year and in the Indian Ocean (80S-30N) by $1.4 \mathrm{~mm} / \mathrm{year}$, it falls by $-0.20 \mathrm{~mm} / \mathrm{year}$ in the Pacific $(80 \mathrm{~S}-67 \mathrm{~N})$. The latter is mainly caused by a loss of mass through transport divergence in the Pacific sector of the Antarctic Circumpolar Current $(-0.42 \mathrm{~Sv})$ that is not balanced by net surface water supply. The consequence of this uneven eustatic rise is a shift of the oceanic center of mass towards the Atlantic and to the north.
\end{abstract}




\section{Introduction}

The mass budget of the ocean is a key problem in the global hydrological cycle as well as in the understanding of sea level change. Recent ocean volume changes are monitored successfully by altimetry. However, the corresponding mass changes - or bottom pressure variations - can be estimated only using secular changes in the geoid provided e.g. from the Gravity Recovery and Climate Experiment (GRACE) mission since 2002. In the past years many authors, e.g. Chen et al. (1998), Minster et al. (1999), Cazanave et al. (2000) or Chambers et al. (2000), attempted to estimate the annual cycle of the global ocean mass balance (eustatic sea level) from altimeric measurements in combination with climatological hydrographic data. Only recently Chambers et al. (2004) published first global ocean mass variations from GRACE. But these data are still too inaccurate and cover a period too short to tell anything about spatial or temporal variability (other than the annual cycle).

To find a consistent reanalysis of the measured sea level rise and its regional distribution it is insufficient to apply local corrections in temperature or sea surface height or vertical adjustment (heave). Only an optimization of the forcing of the ocean that leads to sustained circulation changes and thus indirectly to sea level changes can be successfull. In the present paper the ocean state estimation technique is applied that constrains an ocean general circulation model (OGCM) by data. This offers the possibility to combine altimeric measurements with hydrographic data in a dynamically consistent manner and to look at the oceans mass balance in more detail, in space as well as in time. Using altimetric and hydrographic data for the period 1993-2003 mainly the regional and global trends in the mass balance will be discussed, thus supplementing the papers mentioned above. The utilized model and the data are introduced in the next section followed by a comparison of the model results to data (section 3 ), i.e. to demonstrate how well the model fits the constraints and how it compares to independent data. 
Section 4 then deals with the mass balance of the ocean itself and concluding remarks will be given in section 5 .

\section{Model and Data}

For our purpose we use the Hamburg Large Scale Geostrophic model (LSG, Maier-Reimer and Mikolajewicz 1991). This model was originally designed for climate studies with time scales

of thousands of years (e.g. Maier-Reimer et al. 1993). But in conjunction with its adjoint it has also been used successfully for ocean state estimation (e.g. Wenzel et al. 2001, Wenzel and Schröter 2002, Hellmer et al. 2005). The model version used in this paper has $2^{\circ} \times 2^{\circ}$ horizontal resolution, 23 vertical layers (varying from $20 \mathrm{~m}$ thickness for the top layer to $750 \mathrm{~m}$ for the deepest ones) and the implicit formulation in time allows for a time step of ten days.

The model is very suitable for our purpose, because it has a free surface and conserves mass rather than volume. The usefulness of the model is further improved by adding the steric effects explicitly to the original coding. Now the temporal evolution of the sea surface height $\zeta$ is determined as:

$$
\begin{aligned}
\frac{\partial}{\partial t} \zeta & =\mathrm{P}-\mathrm{E}+\mathrm{R} & & \text { freshwater flux } \\
& +\nabla \cdot \int_{-H}^{\zeta} \vec{v} \mathrm{~d} z & & \text { divergence } \\
& +\left.\int_{-H}^{\zeta} \frac{1}{\alpha} \frac{\partial \alpha}{\partial T}\right|_{S, p} \frac{\partial}{\partial t} T \mathrm{~d} z & & \text { thermosteric effect } \\
& +\left.\int_{-H}^{\zeta} \frac{1}{\alpha} \frac{\partial \alpha}{\partial S}\right|_{T, p} \frac{\partial}{\partial t} S \mathrm{~d} z & & \text { halosteric effect }
\end{aligned}
$$

( $\zeta:$ sea level; $H$ : depth; P: precipitation; E: evaporation; R: river run-off; $T$ : temperature; $S$ : 
salinity; $p$ : pressure; $\alpha=1 / \rho$ : specific volume; $\vec{v}$ : horizontal velocity )

This offers the ability to estimate the single contributions to sea level change, the steric (thermosteric, halosteric) and the eustatic effects (local freshwater balance, mass redistribution) seperately. Please note that the model cannot distinguish between the single contributions to the surface freshwater flux.

The datasets used in the assimilation experiment are:

- monthly sea surface temperatures (SST) for the period 1993-2003 (Reynolds et al. 2002)

- gridded fields of ten day averages of sea surface height anomalies (SSHA) as measured by the TOPEX/Poseidon altimetric mission for the period 1993-2003, provided by Geoforschungszentrum Potsdam (GfZ; S. Esselborn, pers. communication). These anomalies are combined with the SHOM98.2 mean sea surface height (MSSH; CLS) referenced to the EIGEN-GRACE01S geoid (GFZ-G) to give absolute sea surface height values.

- temporal mean transports of mass, freshwater and heat as obtained by different authors and as they are summarized e.g. by Bryden and Imawaki (2001) and by Wijffels (2001). Transport constraints are not applied for the Antarctic Circumpolar Current (ACC).

- the mean annual cycle of temperatures, salinities and horizontal velocities on two sections in the Weddel Sea area, one running across the inner Weddell Sea and the other on the crest of the South Scotia Ridge. These data are taken from a high resolution model of the Weddell Sea (Schodlok et al. 2002) whose water mass characteristics and circulation are in good agreement with local observations.

- the climatological mean temperatures and salinities from the WOCE Global Hydrological Climatology (WGHC; Gouretski and Koltermann 2004) in combination with the mean annual cycle from the most recent World Ocean Atlas (WOA01; Conkright et al. 2002). 
These data are supplied to the assimilation procedure with small weights thus serving only as background information.

In the present paper we do not use any subsurface data others than the afore mentioned background climatology. This work is a first step towards the use of subsurface data. The assimilation of actual temperatures, e.g. from Willes et al. (2004), will be done in the next experiment. At present we retain these data for verification.

There is no direct constraint on the surface freshwater flux in our model. A direct constraint on this flux seems to be inadequate because any data on $\mathrm{P}-\mathrm{E}+\mathrm{R}$ are orders of magnitude more uncertain than what is required here. In this experiment the surface freshwater flux largely plays the role of a residual that is constrained indirectly by the use of the SSHA and SST data: In general the freshwater flux would be able to compensate for any change in the SSHA that cannot be explained by steric effects. But this flux does not only change the volume of the models uppermost layer but the surface salinity as well by keeping the amount of salt in this layer constant. This sets a rough limit to the estimated freshwater fluxes because salinity is constrained to climatology. In addition any eustatic sea level change would cause a halosteric change of the same sign that cannot be neglected locally (e.g. Antonov et al. 2002; Wenzel and Schröter 2002). This gives a further limitation to the estimated flux.

To adjust the model to the data the adjoint method is employed, which is a variational optimization method. The control parameters of this optimization are the models initial temperature and salinity state as well as the forcing fields (windstress, air temperature and surface freshwater flux), whereat the first guess forcing is taken from the monthly NCEP re-analysis fields. In summary the experiment WEDD as analysed in this paper is an update of the WEDEX experiment described in Hellmer et al. (2005). A more detailed desription of the assimilation procedure can be found therein. 


\section{Model - Data Comparison}

The local differences between the models temporal mean SSH and the data are shown in Fig. 1. In most part of the ocean the deviations are well below $5 \mathrm{~cm}$ giving an global RMS value of $11.3 \mathrm{~cm}$. The largest deviations (up to $\pm 30 \mathrm{~cm}$ ) are found in the regions with strong currents, i.e. the western boundary currents as well as the Antarctic Circumpolar Current (ACC). Especially the signature in the ACC region implies that these currents are represented too broadly by the model. The temporal RMS differences between the modeled SSH and the data is shown in Fig. 2. The global RMS value, which is the measure of success in the assimilation, is $2.8 \mathrm{~cm}$ although locally we find higher RMS values (up to $7 \mathrm{~cm}$ ) especially in the tropical Pacific and in the western boundary currents. For the surface temperature (not explicitly shown) the corresponding RMS differences between the model and the data are $0.30 \mathrm{~K}$ for the temporal mean and $0.51 \mathrm{~K}$ for the anomalies.

Figure 3 a shows that the optimized model reproduces the global mean sea level data well (RMS of difference: $0.15 \mathrm{~cm}$ ). This is true especially for the interannual variability, while the amplitude of the annual cycle is slightly underestimated by the model. The latter becomes even more apparent on local scale (not shown) and appears to be a general deficit of the OGCM used which leads to the high RMS values apparent in Fig. 2. Figure 3a also shows that the linear trend in the global sea level change $(3.25 \mathrm{~mm} / \mathrm{year})$ originates mainly from the steric (2.50 $\mathrm{mm} /$ year) while the eustatic contribution $(0.74 \mathrm{~mm} / \mathrm{year})$ adds only a minor part. This is an improvement as compared to the first guess model results (Fig. 4), i.e. using NCEP reanalysis forcing fields. In this case the modeled total sea level trend ( $4.7 \mathrm{~mm} / \mathrm{year})$ splits into $1.7 \mathrm{~mm} /$ year for the steric and $3.0 \mathrm{~mm} /$ year for the eustatic contribution. After the optimization the eustatic trend $(0.74 \mathrm{~mm} /$ year $)$ corresponds well to the $0.87 \mathrm{~mm} /$ year that can be derived by adding together the estimates reported in Cazenave and Nerem (2004): $0.25 \mathrm{~mm} / \mathrm{year}$ sea 
level rise from land water and snow mass, $0.1 \mathrm{~mm} / \mathrm{year}$ from mountain glaciers, $0.13 \mathrm{~mm} / \mathrm{year}$ from Greenland and $0.22 \mathrm{~mm} /$ year from Antarctica. This improvement is directly related to the obtained changes in the mean surface freshwater flux (Fig. 5a), whose spatial structure appears to be not much different from the first guess, i.e. the NCEP derived flux. To accentuate the changes the difference to the first guess is shown in Fig. 5b. Most of the global ocean shows negative changes, i.e. more evaporation. but there also pronounced positve changes especially in the Atlantic.

In contrast to its minor importance for the trend the global eustatic sea level resamples nearly all the 'short term' temporal variability of the global mean sea level (Fig. 3a), while the steric contribution appears more or less as a straight line. Nevertheless we find a small annual cycle in the steric part also, which appears to be in anti-phase with the eustatic.

On global scale the steric contribution to the sea level rise is mainly caused by the thermosteric effect (Fig. 3b) with a positive trend steming from all layers. The halosteric part (Fig. 3c) implies a redistribution of salt from the deeper layers to the top. For the total volume it reflects the global freshwater balance from precipitation, evaporation and run-off (see e.g. Wadhams and Munk 2004) but it is of minor importance. However, it cannot be neglegted regionally and even locally (Antonov et al. 2002; Wenzel and Schröter 2002).

One possibility to judge the global thermosteric sea level rise is to compare the oceans heat content anomalies to independent data. Figure 6 shows the modeled heat content anomaly for the global ocean, whose total trend corresponds to a $1.5 \mathrm{~W} / \mathrm{m}^{2}$ surface heat flux. Within the top 500m the trend compares well to the trend estimated from the analysis of Willis et al. (2004), although no explicit subsurface temperature data are given in the assimilation. Further confidence in our results is obtained by the good correspondence in the spatial distribution as well as in the size of the local trends in upper ocean heat content between our results (Fig. 7) and 
Willis et al. (2004). Figure 6 also indicates that the deeper layers give an essential contribution to the total thermosteric sea level rise which is confirmed by the results shown in Levitus et al. (2005). Regardless of this the trends might be due to a still existing artificial model drift in our case, although the assimilation includes a constraint to minimize deep ocean interannual variability. This constraint reduces e.g. the thermosteric sea level trend steming from the deep ocean (below 2250m) by a factor of two and the halosteric by a factor of ten as compared to the first guess. Anyhow, the deep layers should not be neglegted in general when estimating the oceans water mass budget from sea level change and temperature measurements especially on long timescales. The negligence might be justified when investigating the mean annual cycle only, like e.g. Chen et al. (1998), Minster et al. (1999), Cazanave et al. (2000) or Chambers et al. (2000). Looking on longer periods temperature and salinity changes might be small in the deep layers but they are related to a large volume that amplifies their influence on the sea level (see Fig. 3b,c).

The modeled mass variations (eustatic part, green curve in Fig. 3a) are well represented by the corresponding variations in the bottom pressure field. These variations should be detectable through variations in the geoid estimated e.g. from the GRACE mission once the measurements have been fully analysed. The available GRACE data (F. Flechtner, pers. communication) are still rather preliminary and should be treated with caution. Nevertheless, Chambers et al. (2004) show that the global eustatic sea level variations detected by GRACE fit well to the mean annual cycle deduced from TOPEX measurements (corrected for the steric effect using WOA01 data). Here we do a comparison on different scales using the last two years of the modelled bottom pressure. Examples are given in Fig. 8 for: the global ocean, the total Atlantic, the total Pacific and for the western part of the tropical Pacific, respectively. We find good correspondence in amplitude and phase between the modeled bottom pressure variations and the GRACE data (given in cm water equivalent) for the global ocean (Fig. 8a). The correspondence diminishes 
when looking at smaller areas and gets even unacceptable on scales like e.g. the western tropical Pacific (Fig. 8d). The poor correspondence on more local scales is not directly related to the RMS errors in the retrieved SSHA (Fig. 2). Nevertheless it might be due to the above mentioned model deficit, i.e. underestimating the amplitude of the annual cycle. Furthermore there is still a deficiency of the GRACE data as well, which are represented by spherical harmonics and include the much stronger signals from the hydrological cycle of the land surface. But the good agreement between model and data on large scales shows that the data will be suitable to constrain modelled ocean mass variations at least on regional to global scales once the quality of the data has been improved. Because hydrographic data are sparse in space and time this information is valuable to better the estimate of the actual steric sea level change (e.g. Jayne et al. 2003).

\section{Ocean Mass Balance}

The good correspondence of the model results to the Willis et al. (2004) analysis as well as to the GRACE data on largest scales gives confidence to look into the model results in more detail. Figure 9 shows the models local sea level trends as splitted into the total steric contribution (Fig. 9b) and the eustatic part (Fig. 9c). Locally as well as in the global mean most of the total trend (Fig. 9a) is due to the steric contribution while the eustatic part is much smaller but not negligible. Corresponding to the mean freshwater flux into the ocean the global mean eustatic sea level trend is $0.74 \mathrm{~mm} / \mathrm{year}$, which is about three times smaller than the steric trend $(2.50 \mathrm{~mm} /$ year). Furthermore, compared to the steric part (Fig. 9b) the eustatic trends do not show much spatial variablity. Throughout the Atlantic and the Indian Ocean the eustatic trends are positive on a fairly constant level ( $\sim 2 \mathrm{~mm} / \mathrm{year})$ while they are near zero or slightly negative in most parts of the Pacific (see also Tab. 1). The most conspicuous feature in Fig. 9c 
are the strong negative trends west of Drake Passage leaking into the Scotia Sea (down to $20 \mathrm{~mm} /$ year).

The global ocean mass exhibits a strong seasonal cycle (Fig. 10), aside which an interannual variability is visible with a slight decrease in mass during 1993-1995 followed by a stronger rise. This results in an overall positive trend for the total period (1993-2003) consistent with the global mean of the eustatic trends (Fig. 9c). This reveals that the magnitude of the trends estimated for this period could be the consequence of looking only at a part of a longtime oszillation, at least by part. Using all 1993-2003 model data, with the longer periods (red curve in Fig. 10) removed from the timeseries, we find a mean annual cycle of $1.66 \times 10^{15} \mathrm{~kg}$ in amplitude and 278.4 degr in phase. The corresponding values for the semiannual cycle are $0.15 \times 10^{15} \mathrm{~kg}$ and $119.6 \mathrm{degr}$, respectively. While the phases (defined as the day of maximum value since January 1) fit well to earlier estimates by Chen et al. (1998), Cazenave et al. (2000) or Chambers et al. (2004), the amplitudes for the corresponding eustatic sea level (4.6 mm and $0.42 \mathrm{~mm}$ respectively) appear to be smaller than theirs, which obviously is due to the different methods / time periods used for the estimate.

The residuals of the mean mass balance for the single ocean basins are small as compared to the corresponding transport values, (Tab. 1, Fig. 11) but they represent the regional eustatic changes well. The mass balances are positive for all basins (the basins gain mass) except for the South Pacific, that is balanced $\left(-0.04 \mathrm{mSv}^{1}\right)$, and especially for the Pacific sector of the ACC $(-2.35 \mathrm{mSv})$. In the latter area the divergence in the ocean mass transport $(-0.420 \mathrm{~Sv})$ is not totally compensated by the net freshwater supply to the ocean through the surface $(0.417 \mathrm{~Sv})$, which leads to the afore mentioned anomalous strong eustatic sea level fall. Looking at the other basins in more detail one finds that the mass surplus results from different balances: in the tropical region of the Indian Ocean and the Pacific the net input by precipitation is not

\footnotetext{
${ }^{1} 1 \mathrm{~Sv}=10^{9} \mathrm{~kg} / \mathrm{s} ; 1 \mathrm{mSv}=10^{6} \mathrm{~kg} / \mathrm{s}$
} 
compensated by mass divergence, while for the northern and southern ocean basins the mass convergence is not balanced by net evaporation. Within the ACC there is net precipitation in all sectors overcompensating the mass transport divergence (except for the Pacific sector, see above). In summary most of the mass gain of the ocean goes to the northern hemisphere and especially to the Atlantic Ocean. This also becomes apparent through the changes in the position of the oceans center of mass. At the end of the model integration the center of mass is displaced by $\Delta X=771 \mathrm{~cm}, \Delta Y=213 \mathrm{~cm}$ and $\Delta Z=573 \mathrm{~cm}$. In contrast, adding the final mass surplus of $3 \times 10^{15} \mathrm{~kg}$ (Fig. 10) uniformly to the ocean $(\Delta \zeta \approx 0.8 \mathrm{~cm}$ ) would shift the oceanic center of mass by about $\Delta X=-42 \mathrm{~cm}, \Delta Y=-17 \mathrm{~cm}$ and $\Delta Z=-45 \mathrm{~cm}$, i.e. much less and into the opposite direction.

\section{Conclusions}

The oceans mass budget for the period 1993-2003 is estimated by constraining the LSG ocean model with hydrographic data, mean ocean transport estimates and sea level data derived from the TOPEX/Poseidon mission. A comparison with independent data, upper ocean heat content (Willis et al. 2004) and preliminary bottom pressure estimates from GRACE, shows that the constrained model works fairly well.

The global ocean mass exhibits a pronounced annual cycle (amplitude: $1.66 \times 10^{15} \mathrm{~kg}$; phase: $278.4 \mathrm{degr}$ ) that is superimposed by interannual variability. The resulting positive trend, valid for the chosen period 1993-2003, corresponds to a $0.74 \mathrm{~mm} /$ year eustatic global sea level rise. On local or regional scale the mass changes (eustatic sea level changes) are the residual of the horizontal mass transport divergence and the surface fluxes. Compared to the steric changes the eustatic sea level varies on very large scales. In summary there is net mass gain in all basins, except for the Pacific sector of the ACC, but this gain is not evenly distributed. It is stronger 
in the northern than in the southern hemisphere and stronger in Atlantic and Indian Ocean than in the Pacific. This unequal distribution of mass gain in the single basins appears to be caused mainly by internal redistribution of mass.

Although global analyses like Willis et al. (2004) have their own deficiencies, the next step will be to include more subsurface information directly into the assimilation scheme to improve the modeled steric sea level change and by this to upgrade the eustatic estimates. Furthermore, once the GRACE data have been improved, the alternate approach will be possible too: to better the ocean heat content estimates, steric sea level variations by constraining the bottom pressure variations. This route was proposed e.g. by Jayne et al. (2003) and appears to be necessary to follow because direct hydrographic measurements are sparse in space and time.

Acknowledgements: The authors thank Carl Wunsch for his inspiring ideas. Inverse modelling, data assimilation and satellite altimetry started for us more than twenty years ago based on and guided by his pioneering work and lead finally to this paper.

Furthermore we wish to acknowledge Saskia Esselborn (GfZ Potsdam) for providing the reprocessed TOPEX/Poseidon data and Frank Flechtner (GfZ Potsdam) for providing the preliminary GRACE data. The ocean center of mass was calculated using a routine from IERS kindly provided by Richard Gross (JPL). 


\section{References}

Antonov J. I., S. Levitus and T. B. Boyer, 2002: Steric sea level variations during 1957-1994: Importance of salinity, Journal of Geophysical Research, 107 (C12), 8013, doi: 10.1029/2001JC00964

Bryden H. L. and Shiro Imawaki, 2001: Ocean Heat Transport, Ocean Circulation and Climate, Siedler G., J. Church and J. Gould, Ed., Academic Press, International Geophysics Series Vol 77, pp 455-474

Cazenave A., F. Remy, K. Dominh and H. Douville, 2000: Global ocean mass variations, continental hydrology and the mass balance of Antarctica ice sheeet at seasonal time scale, Geophysical Research Letters, 27, No.22, 3755-3758

Cazenave A. and R. S. Nerem, 2004: Present-day sea level change: observations and causes, Review of Geophysics, 42, RG3001, 1-20

Chambers D. P., J. Chen, R. S. Nerem and B. D. Tapley, 2000: Interannual mean sea level change and the earth's water mass budget, Geophysical Research Letters, 27, No.19, 30733076

Chambers D. P., J. Wahr and R. S. Nerem, 2004: Preliminary observations of global ocean mass variations with GRACE, Geophysical Research Letters, 31, L13310, doi: 10.1029/2004GL020461

Chen J. L., C. R. Wilson, D. P. Chambers, R. S. Nerem and B. D. Tapley, 1998: Seasonal global water mass budget and mean sea level variations, Geophysical Research Letters, 25, No.19, $3555-3558$

CLS : SHOM98.2 mean sea surface, http://www.cls.fr/html/oceano/projets/mss/cls_shom_en.html 
Conkright M. E., R. A. Locarnini, H. E. Garcia, T. D. O’Brien, T. P. Boyer, C. Stephens and J. I. Antonov, 2002: World Ocean Atlas 2001: Objective Analysis, Data Statistics and Figures, CD-ROM Documentation, National Oceanographic Data Center, Silver Springs, MD, 17pp.

GFZ-G : EIGEN-GRACE01S geoid, http://op.gfz-potsdam.de/grace/index_GRACE.html

Gouretski V. V. and K. P. Koltermann, 2004: WOCE Global Hydrographic Climatology, A Technical Report, Berichte des Bundesamtes für Seeschifffahrt und Hydrographie, No. 35, 50pp. + 2 CD-ROM

Hellmer H. H., M. P. Schodlok, M. Wenzel and J. G. Schröter, 2005: On the influence of adequate Weddell Sea characteristics in a large-scale ocean circulation model, Ocean Dynamics, doi: 10.1007/s10236-005-0112-4

Jayne S. R., J. M. Wahr and F. O. Bryan, 2003: Observing ocean heat content using satellite gravity and altimetry, Journal of Geophysical Research, 108 (C2), 3031, doi: 10.1029/2002JC001619

Levitus S., J. Antonov and T. Boyer, 2005: Warming of the world, ocean 1955-2003, Geophysical Research Letters, 32, L02604, doi: 10.1029/2004GL021592

Maier-Reimer E. and U. Mikolajewicz, 1991: The Hamburg Large Scale Geostrophic Ocean General Circulation Model (Cycle 1), Tech. Report, 2, Deutsches Klimarechenzentrum, Hamburg

Maier-Reimer E., U. Mikolajewicz, and K. Hasselmann, 1993: Mean circulation of the Hamburg LSG OGCM and its sensitivity to the thermohaline surface forcing, Journal of Physical Oceanography, 23, 731-757

Minster J. F., A. Cazenave, Y. V. Serafini, F. Mercier, M. C. Gennero and P. Rogel, 1999: 
Annual cycle in the mean sea level from Topex-Poseidon and ERS-1: inference on the global hydrological cycle, Global and Planitary Change, 20, 57-66

Reynolds R. W., N. A. Rayner, T. M. Smith, D. C. Stokes and W. Wang, 2002: An improved in situ and satellite SST analysis for climate, Journal of Climate, 15, 1609-1625

Schodlok M. P., H. H. Hellmer, and A. Beckmann, 2002: On the transport, variability, and origin of dense water masses crossing the South Scotia Ridge, Deep Sea Research II, 49, $4807-4825$

Wadhams P. and W. Munk, 2004: Ocean freshening, sea level rise, sea ice melting, Geophysical Research Letters, 31, L11311, doi: 10.1029/2004GL020029

Wenzel M., J. Schröter and D. Olbers, 2001: The annual cycle of the global ocean circulation as determined by 4D Var data assimilation, Progress in Oceanography, 48, 73-119

Wenzel M. and J. Schröter, 2002: Assimilation of TOPEX/POSEIDON data in a global ocean model: differences in 1995 - 1996, Physics and Chemistry of the Earth, 27, 1433-1437

Wijffels S. E., 2001: Ocean Transport of Fresh Water, Ocean Circulation and Climate, Siedler G., J. Church and J. Gould, Ed., Academic Press, International Geophysics Series Vol 77, pp $475-488$

Willis J. K., D. Roemmich and B. Cornuelle, 2004: Interannual variability in the upper ocean heat content, temperature and thermosteric expansion on global scales, Journal of Geophysical Research, 109, C12036, doi: 10.1029/2003JC002260 
Table 1: Mean Oceanic Mass Balance for 1993-2003

\begin{tabular}{|l|c|c|c|c|c|c|}
\hline & \multicolumn{2}{|c|}{ horizontal transport } & surface & total & eustatic \\
ocean basin & inflow & outflow & in + out & flux & balance & trend \\
[ Sv ] & [ Sv ] & [ Sv ] & [ Sv ] & [ mSv ] & [mm/year] \\
\hline \hline Arctic & 0.407 & -0.532 & -0.125 & 0.126 & 1.06 & 2.19 \\
\hline \hline trop. Indian & 9.463 & -9.610 & -0.148 & 0.149 & 1.61 & 1.70 \\
South Indian & 9.610 & -9.195 & 0.415 & -0.414 & 0.91 & 1.81 \\
ACC - Indian & 136.09 & -136.16 & -0.066 & 0.067 & 0.83 & 0.84 \\
\hline total Indian & 136.36 & -136.16 & 0.201 & -0.198 & 3.35 & 1.37 \\
\hline \hline North Pacific & 0.600 & -0.407 & 0.193 & -0.192 & 0.40 & 0.24 \\
trop. Pacific & 9.493 & -10.063 & -0.569 & 0.570 & 0.87 & 0.46 \\
South Pacific & 10.014 & -9.493 & 0.521 & -0.521 & -0.04 & -0.03 \\
ACC - Pacific & 136.16 & -136.57 & -0.420 & 0.417 & -2.35 & -2.25 \\
\hline \hline total Pacific & 136.16 & -136.43 & -0.275 & 0.274 & -1.12 & -0.20 \\
\hline \hline Nouth Atlantic & 0.245 & -0.076 & 0.169 & -0.168 & 0.91 & 2.47 \\
\hline trop. Atlantic & 0.340 & -0.245 & 0.095 & -0.093 & 1.92 & 2.71 \\
\hline total Atlantic & 127.09 & -126.95 & 0.152 & -0.146 & 5.68 & 1.82 \\
\hline \hline
\end{tabular}

${ }^{a}$ The global outflow goes to the Mediterranean Sea (not included in the Atlantic balance) ACC: Antarctic Circumpolar Current

$1 \mathrm{~Sv}=10^{9} \mathrm{~kg} / \mathrm{s} ; 1 \mathrm{mSv}=10^{6} \mathrm{~kg} / \mathrm{s}$ 


\section{Figures Captions}

Fig.1: Local difference between the models MSSH and the corresponding data mean. The contour intervall is $10 \mathrm{~cm}$. The models coastline is given by the thick black line and the grey shading within the ocean indicate areas with no SSHA data given.

Fig.2: Temporal RMS of the difference between modeled SSHA and the TOPEX/Poseidon data. The contour intervall is $1 \mathrm{~cm}$. The models coastline is given by the thick black line and the grey shading within the ocean indicate areas with no SSHA data given.

Fig.3: (a) Global mean sea level anomaly from the assimilation experiment WEDD as compared to the TOPEX/Poseidon data. Additionally the modeled steric and eustatic contributions are shown. The thermosteric and the halosteric contributions from different depth ranges are shown in (b) and (c) respectively

Fig.4: same as Fig.3a but for the first guess, i.e. using NCEP re-analysis forcing fields. Note that the first guess value for the eustaic trend is about four times as high as after optimization.

Fig.5: (a) optimized surface freshwater flux and (b) its difference to the first guess (NCEP re-analysis forcing). The contour intervalls are $500 \mathrm{~mm} /$ year and $100 \mathrm{~mm} /$ year respectively.

Fig.6: The models global ocean heat content anomaly for the depth ranges [ $\zeta-512 \mathrm{~m}]$, [5122250m], [2250m-bottom] and [ל-bottom]. For comparison the top 500m heat content anomaly derived from the analysis of Willis et al. (2004) is shown also.

Fig.7: Local trend of the upper ocean heat content $[\zeta-700 \mathrm{~m}]$. Contour intervall: $2 \mathrm{~W} / \mathrm{m}^{2}$

Fig.8: Area mean bottom pressure anomalies as compared to the GRACE geoid variations (given in cm water equivalent) for (a) the global ocean, (b) the Atlantic $(55 \mathrm{~S}-65 \mathrm{~N})$, (c) the Pacific (55S-65N) and (d) for the western part of the tropical Pacific (20S-20N/140E-150W).

Fig.9: Modeled local sea level trends (a) and its steric (b) and eustatic (c) component. Contour 
intervall: $2 \mathrm{~mm} / \mathrm{year}$

Fig.10: Variations in the total mass of the ocean relative to its initial value (Jan, 1993). The red curve is filtered to remove the annual and semi-annual cycle.

Fig.11: Temporal mean mass balance of the ocean. Horizontal transports are given on a white background (red: eastward and northward respectively, blue: southward). The transports through the area surfaces are given on a red background for into the ocean and on blue for out of the ocean. The overall background shading regives the mean surface freshwater flux (Fig.5a). The balances of the single ocean basins are summarized in Tab.1 


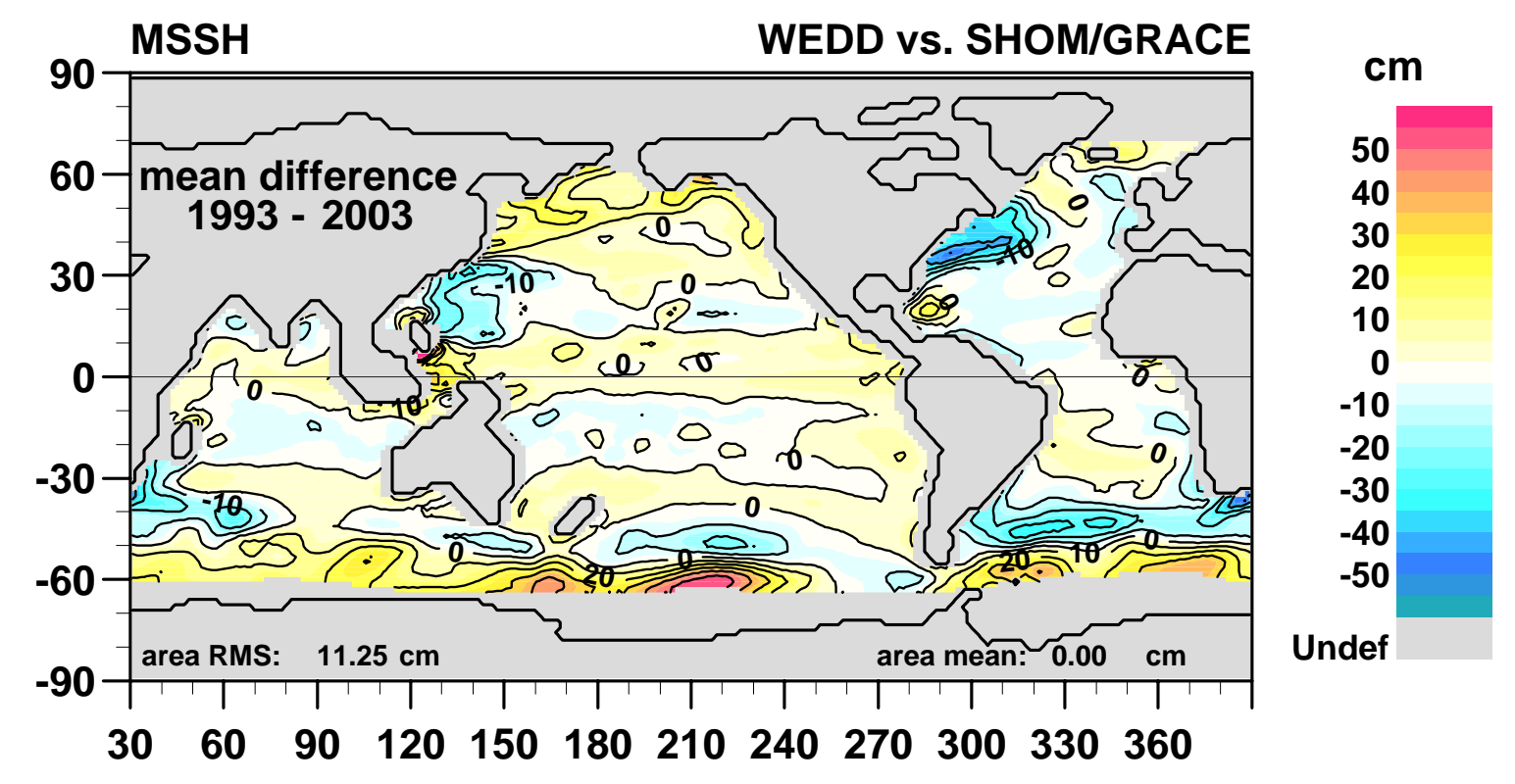

Figure 1: Local difference between the models MSSH and the corresponding data mean. The contour intervall is $10 \mathrm{~cm}$. The models coastline is given by the thick black line and the grey shading within the ocean indicate areas with no SSHA data given. 


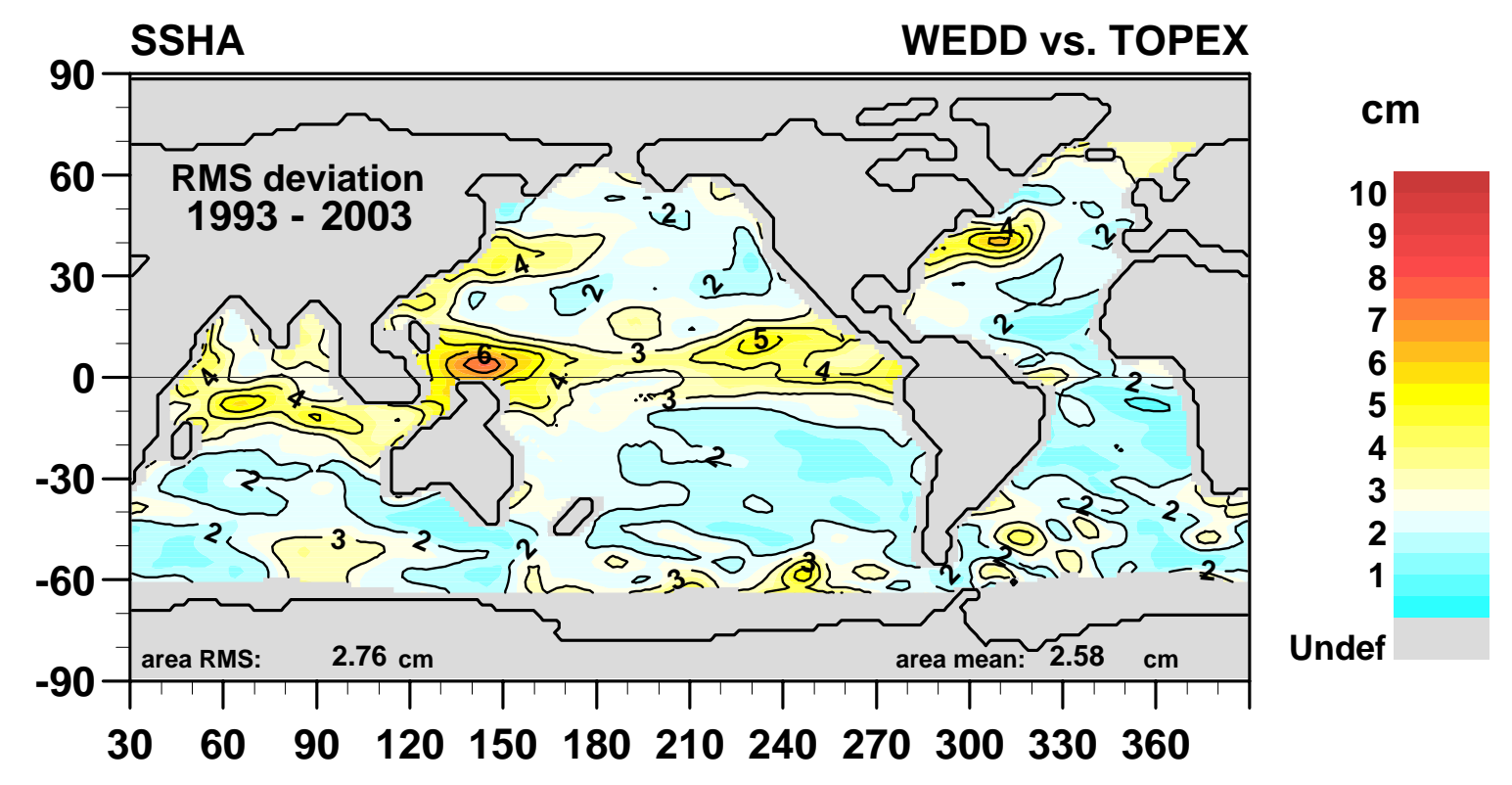

Figure 2: Temporal RMS of the difference between modeled SSHA and the TOPEX/Poseidon data. The contour intervall is $1 \mathrm{~cm}$. The models coastline is given by the thick black line and the grey shading within the ocean indicate areas with no SSHA data given. 

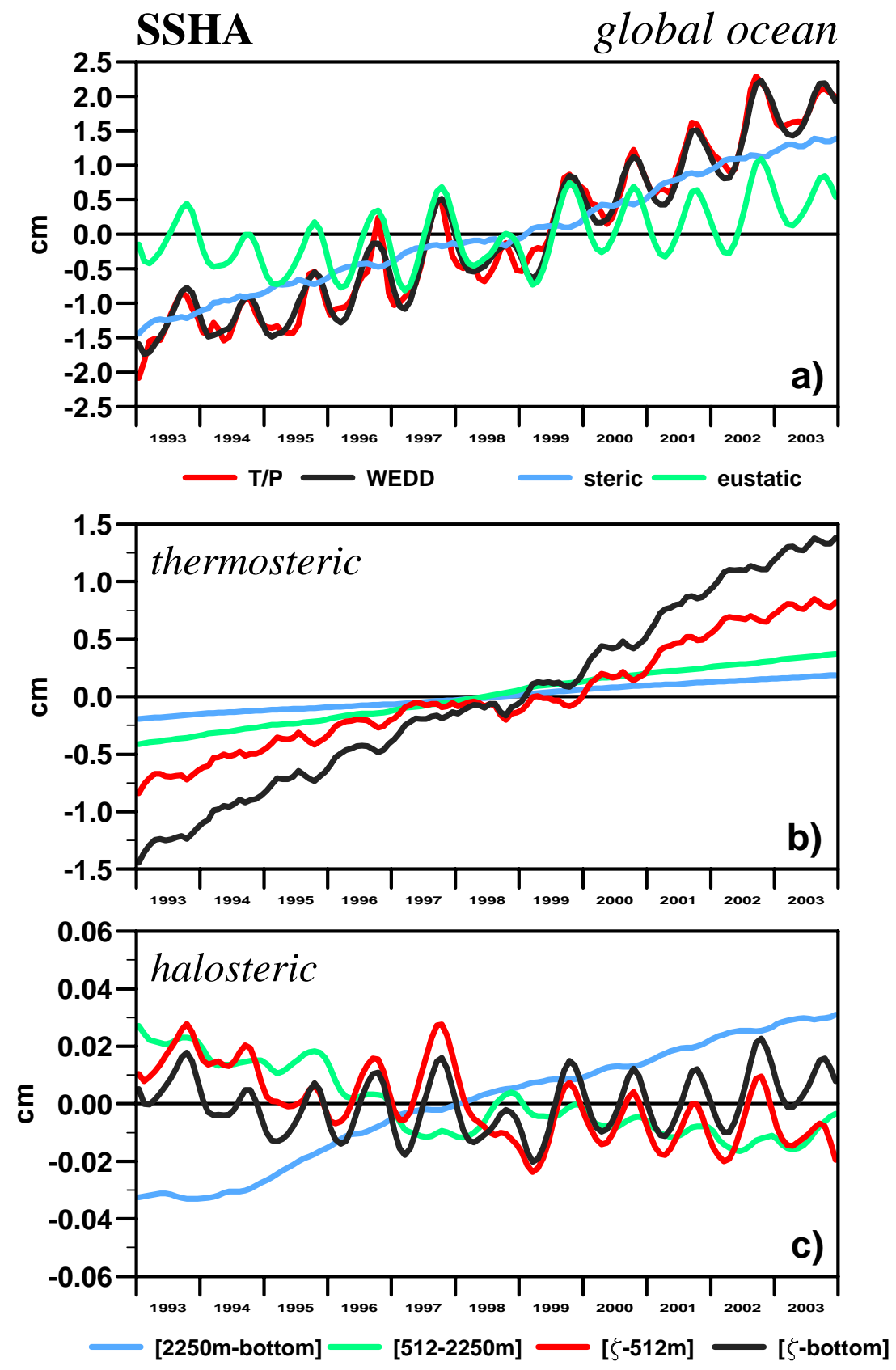

Figure 3: (a) Global mean sea level anomaly from the assimilation experiment WEDD as compared to the TOPEX/Poseidon data. Additionally the modeled steric and eustatic contributions are shown. The thermosteric and the halosteric contributions from different depth ranges are shown in (b) and (c) respectively 


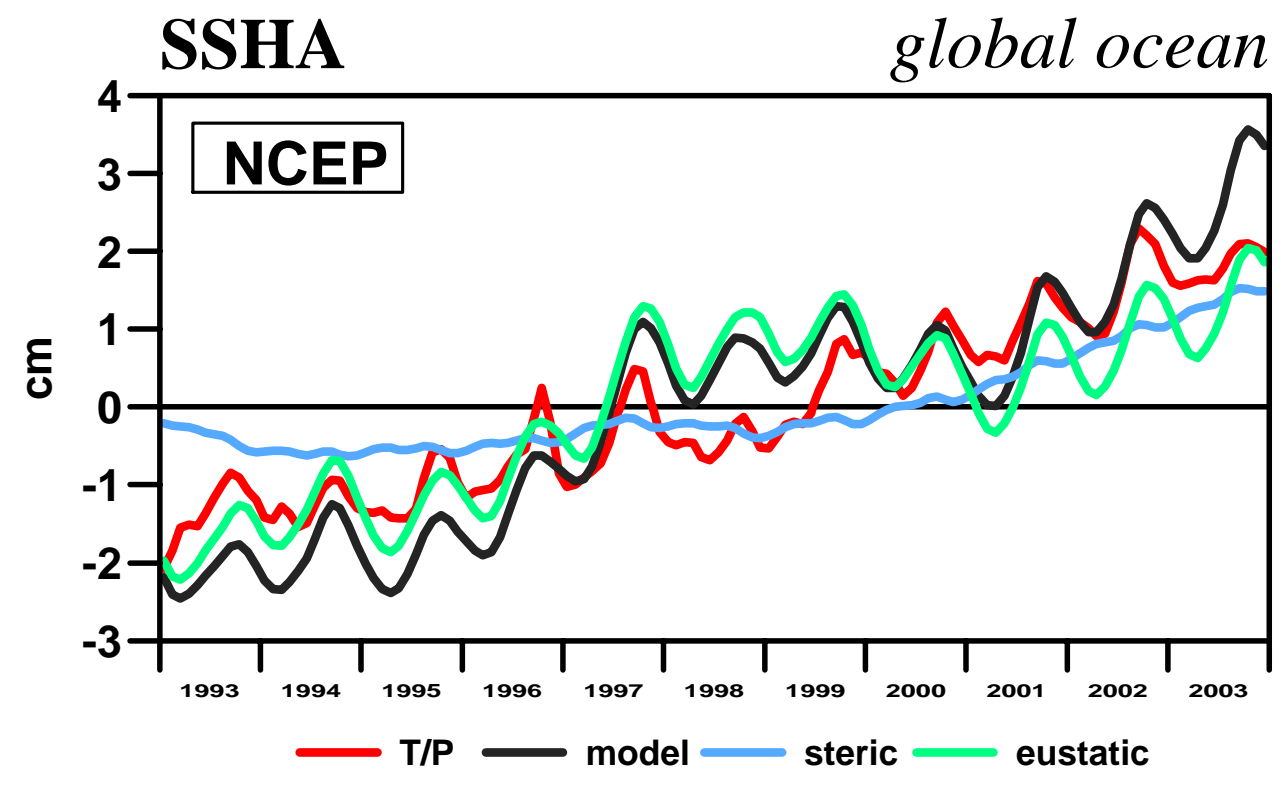

Figure 4: same as Fig.3a but for the first guess, i.e. using NCEP re-analysis forcing fields. Note that the first guess value for the eustaic trend is about four times as high as after optimization. 


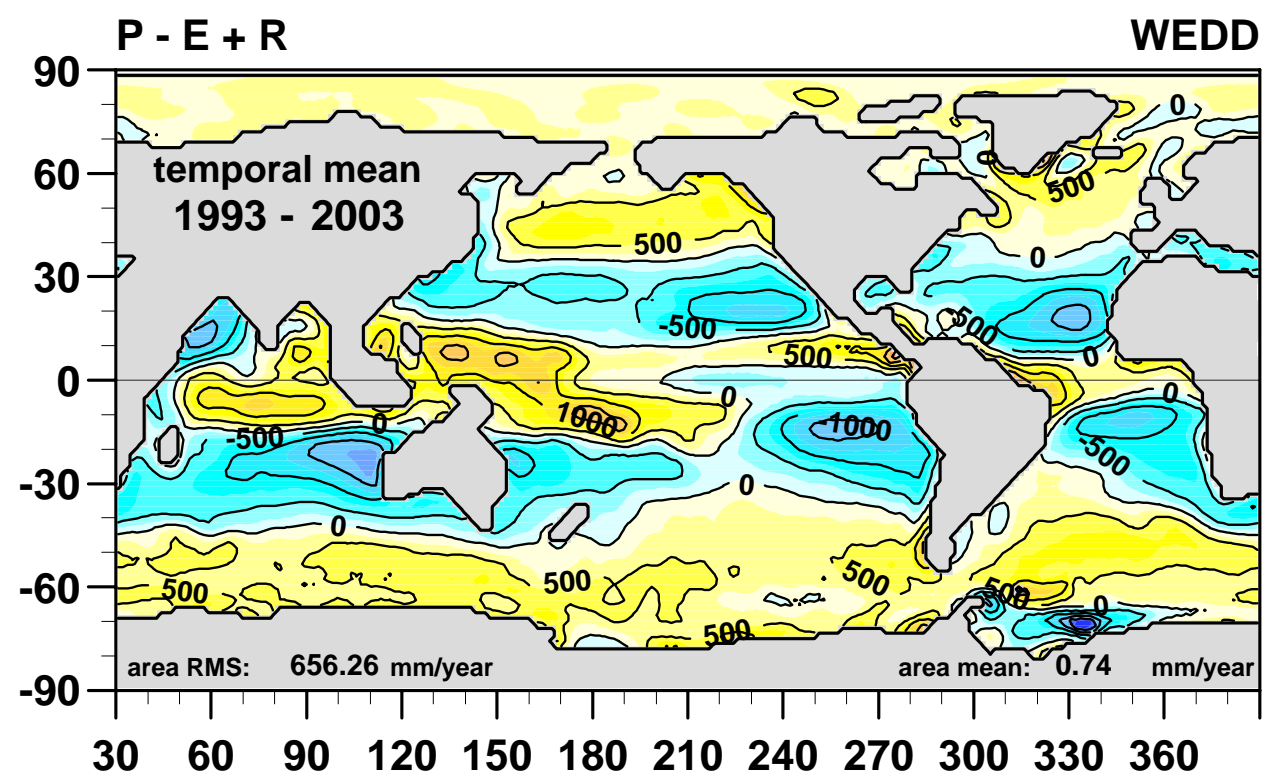

(a)
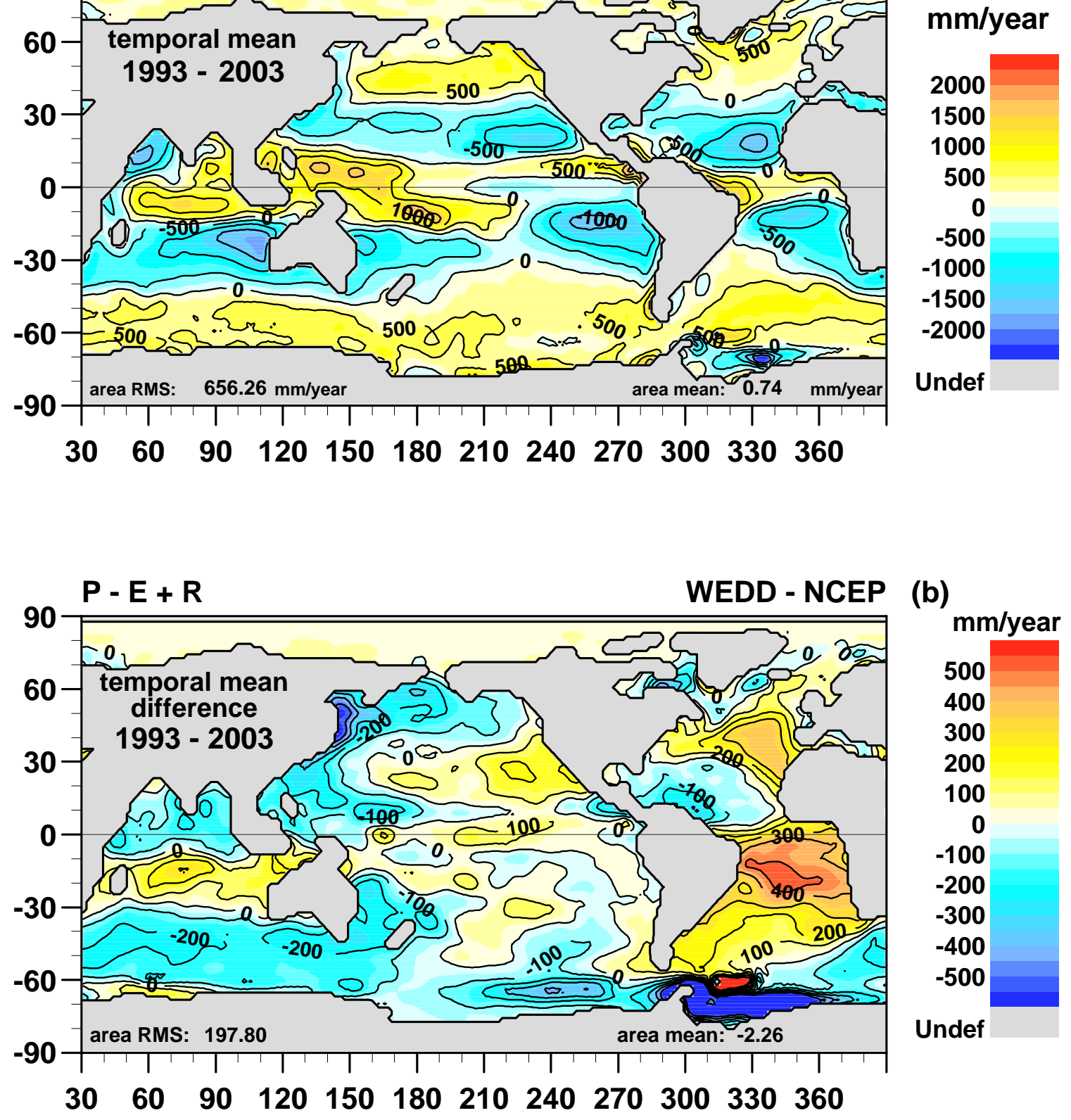

(b) mm/year 500 400 300 200 100 0 $-100$ $-200$ $-300$ $-400$ $-500$ Undef

Figure 5: (a) optimized surface freshwater flux and (b) its difference to the first guess (NCEP re-analysis forcing). The contour intervalls are $500 \mathrm{~mm} /$ year and $100 \mathrm{~mm} /$ year respectively. 


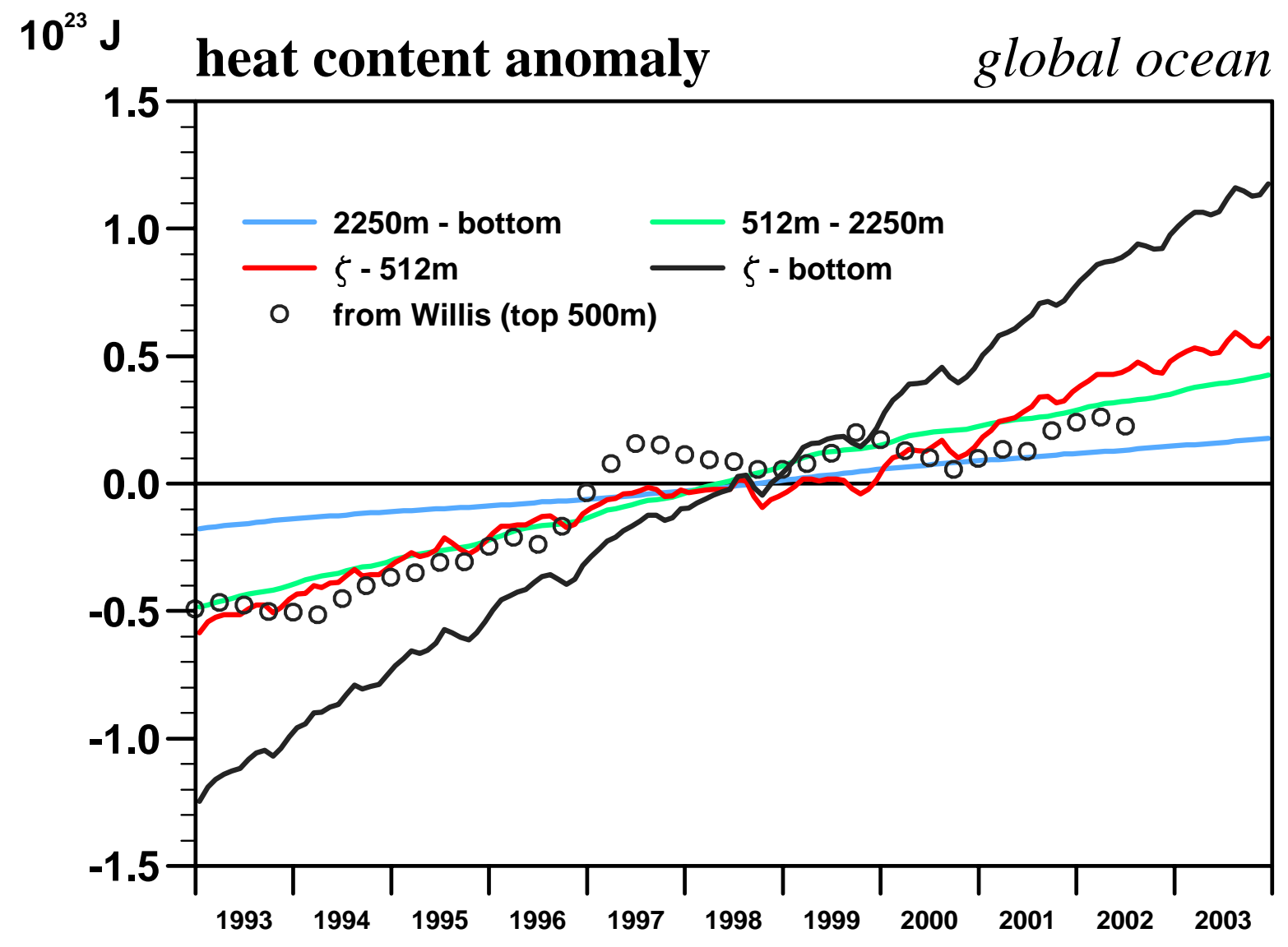

Figure 6: The models global ocean heat content anomaly for the depth ranges $[\zeta-512 \mathrm{~m}]$, [5122250m], [2250m-bottom] and [ $\zeta$-bottom]. For comparison the top 500m heat content anomaly derived from the analysis of Willis et al. (2004) is shown also. 


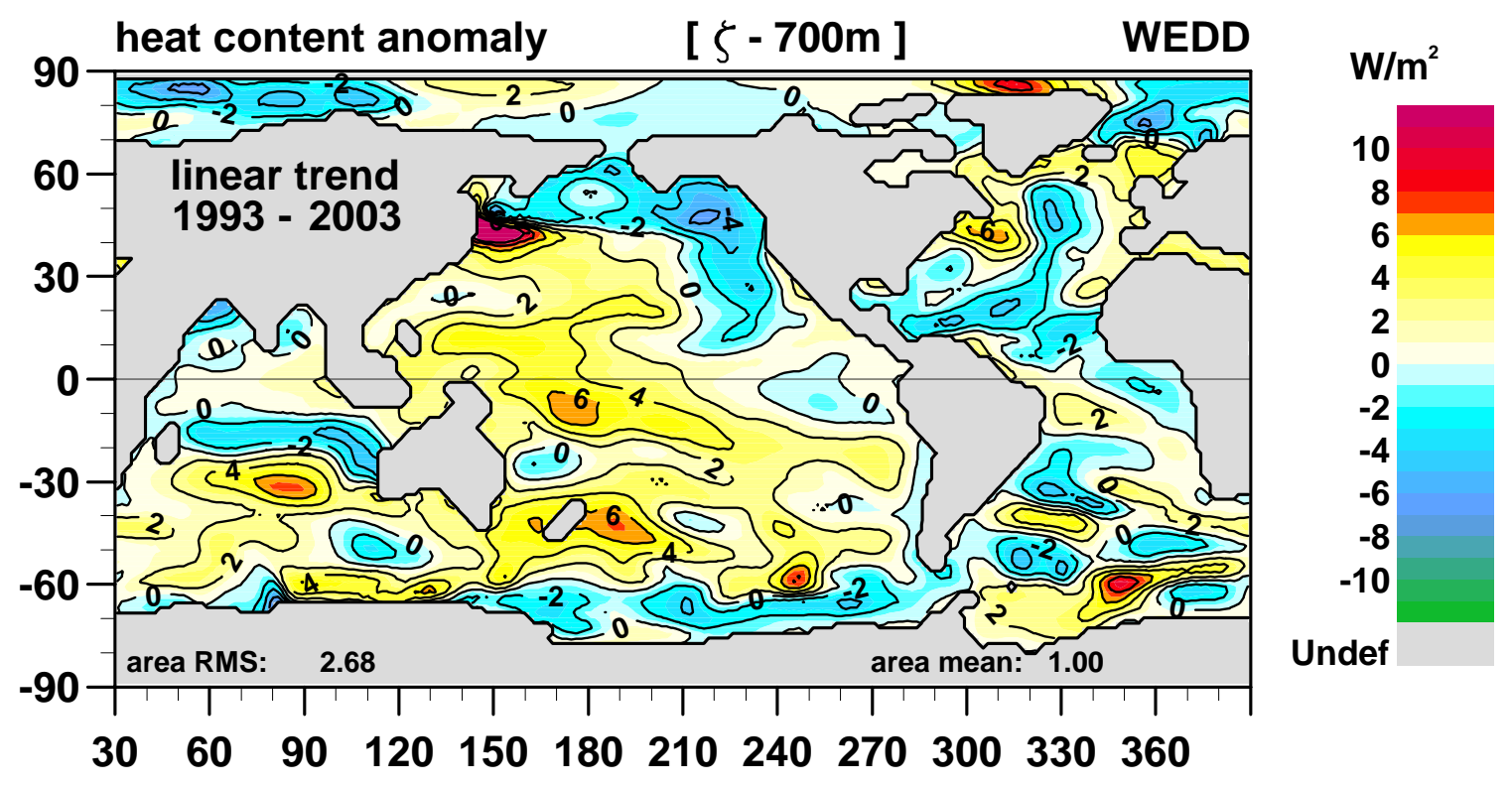

Figure 7: Local trend of the upper ocean heat content $[\zeta-700 \mathrm{~m}]$. Contour intervall: $2 \mathrm{~W} / \mathrm{m}^{2}$ 

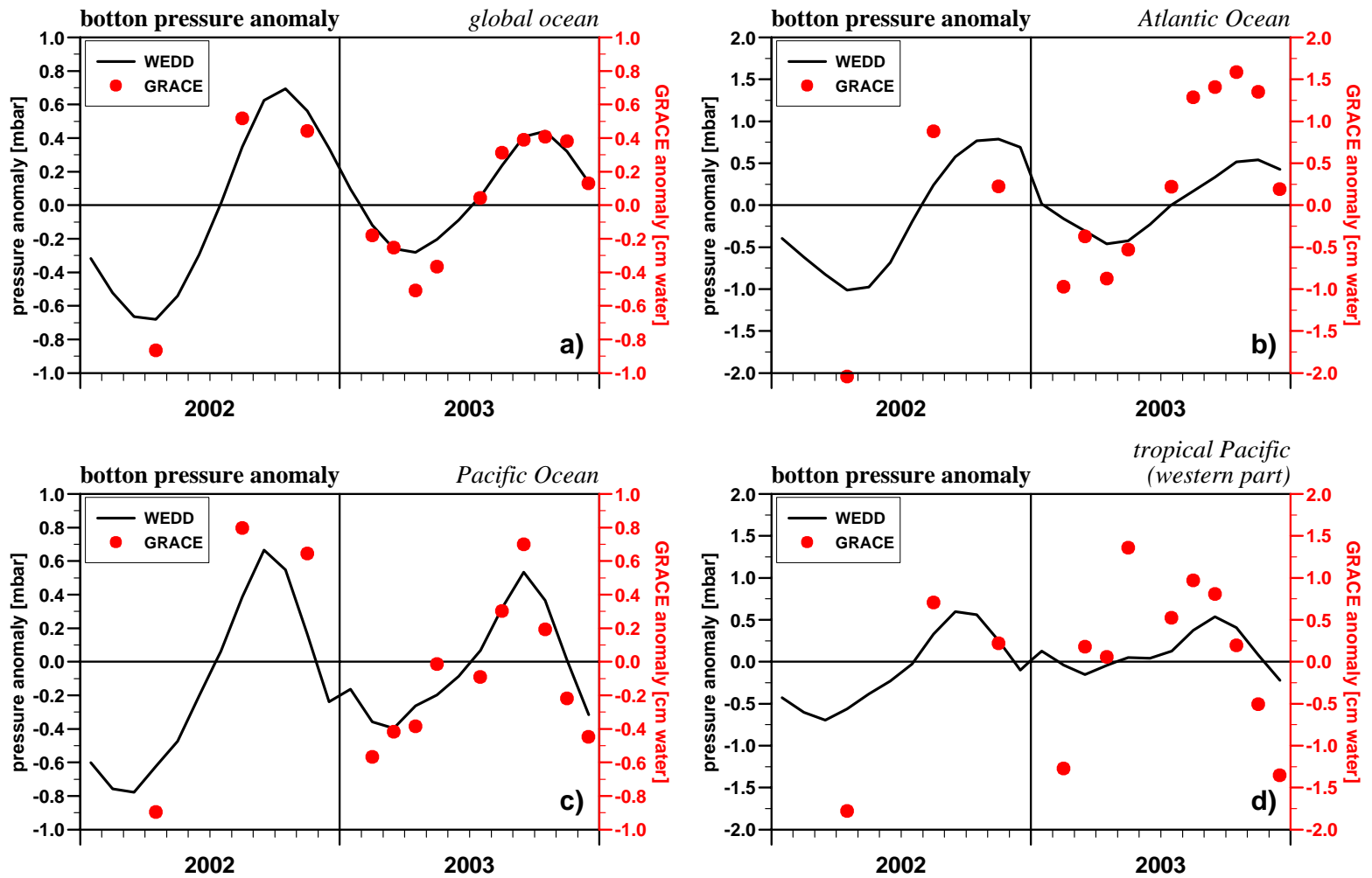

Figure 8: Area mean bottom pressure anomalies as compared to the GRACE geoid variations (given in $\mathrm{cm}$ water equivalent) for (a) the global ocean, (b) the Atlantic $(55 \mathrm{~S}-65 \mathrm{~N})$, (c) the Pacific (55S-65N) and (d) for the western part of the tropical Pacific (20S-20N/140E-150W). 


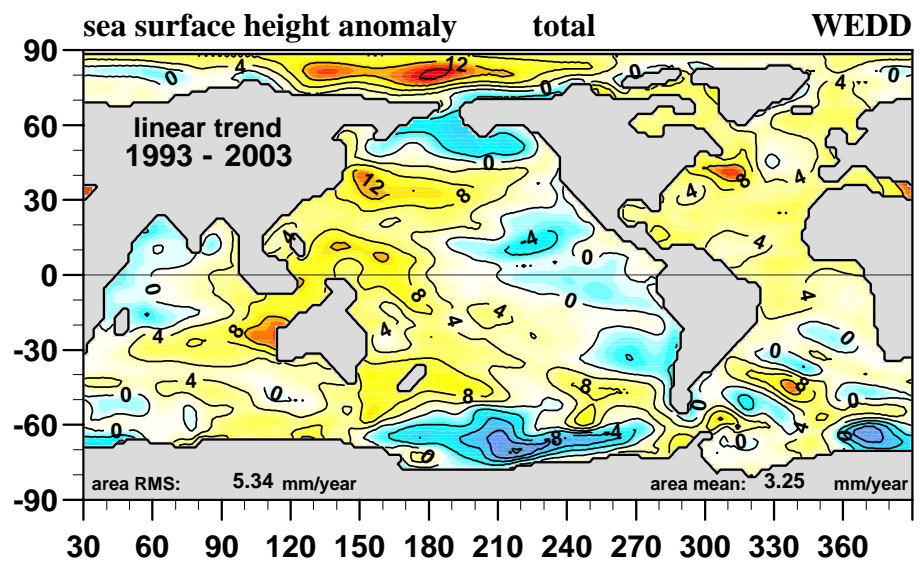

(a)

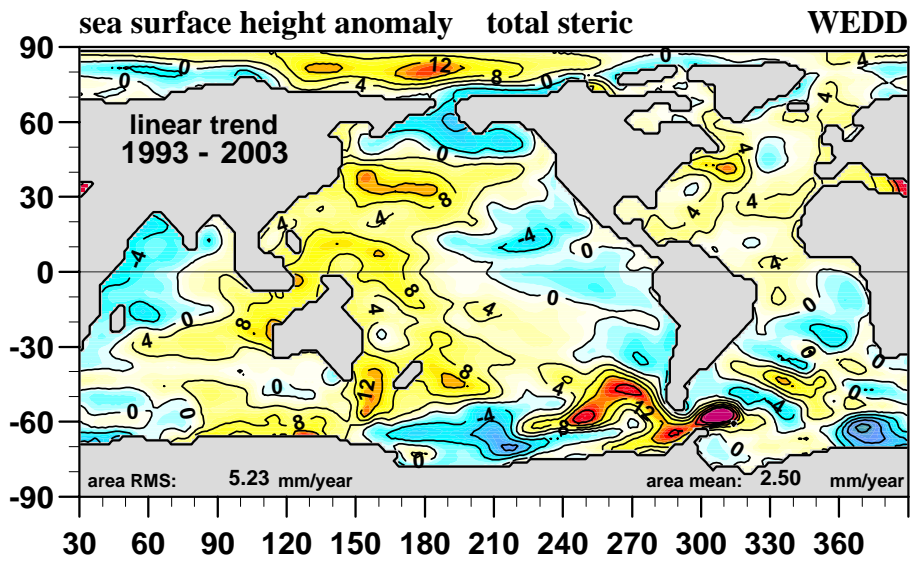

(b)

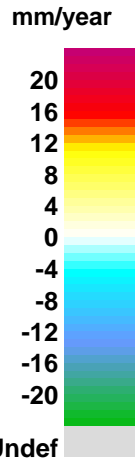

Undef

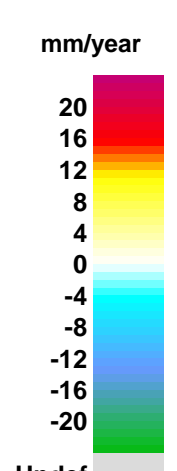

Undef

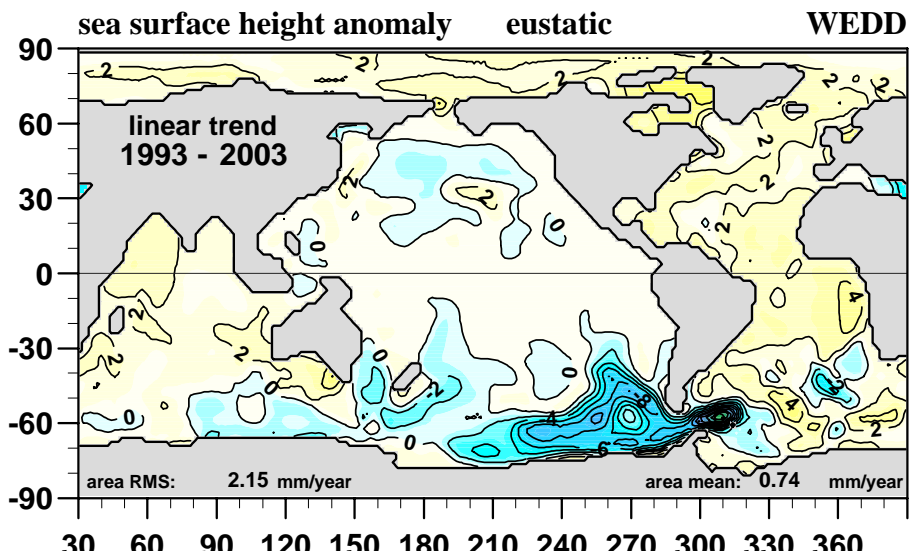

(c)

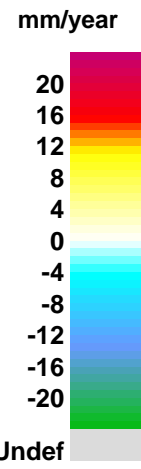

Figure 9: Modeled local sea level trends (a) and its steric (b) and eustatic (c) component. Contour intervall: $2 \mathrm{~mm} / \mathrm{year}$ 


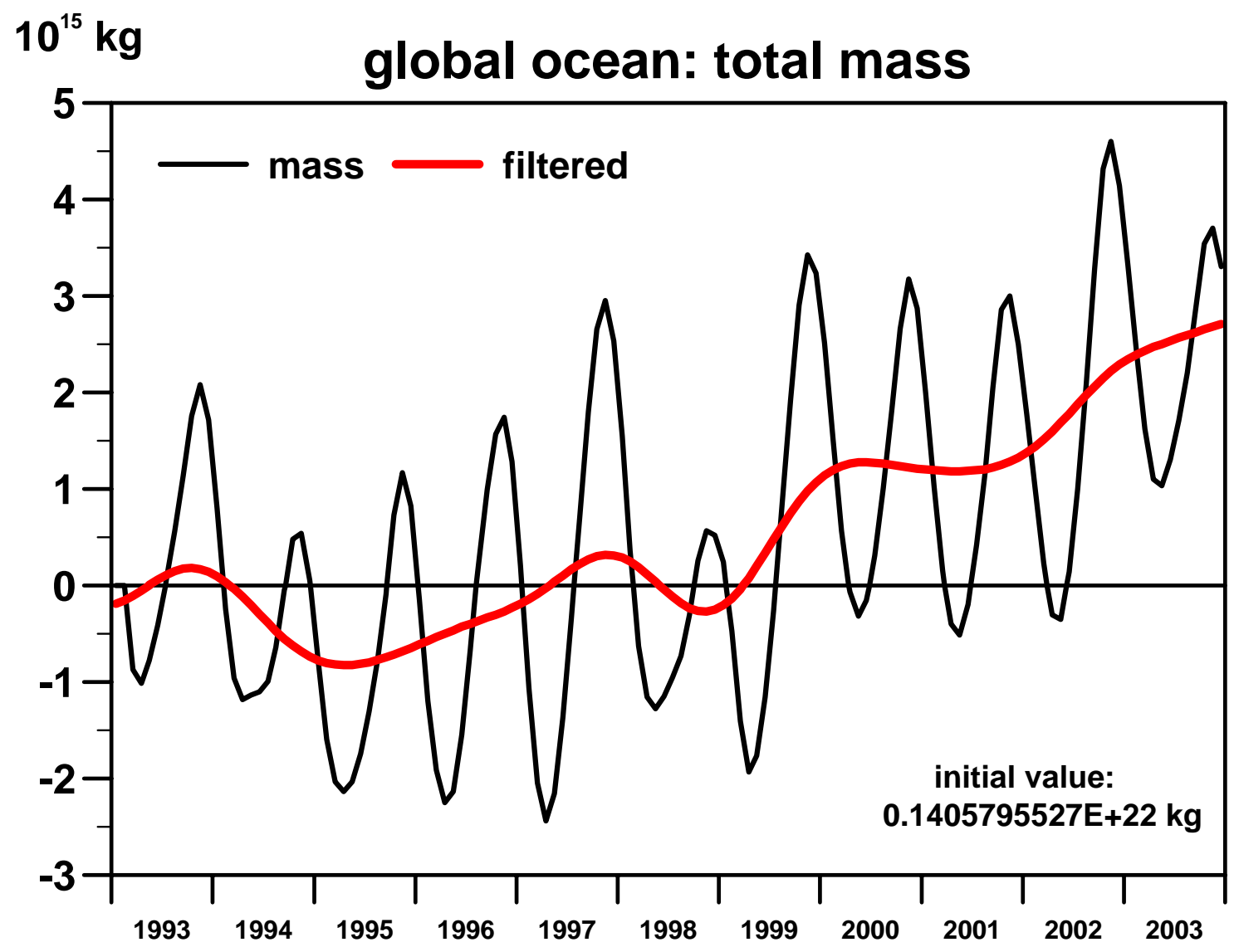

Figure 10: Variations in the total mass of the ocean relative to its initial value (Jan, 1993). The red curve is filtered to remove the annual and semi-annual cycle. 


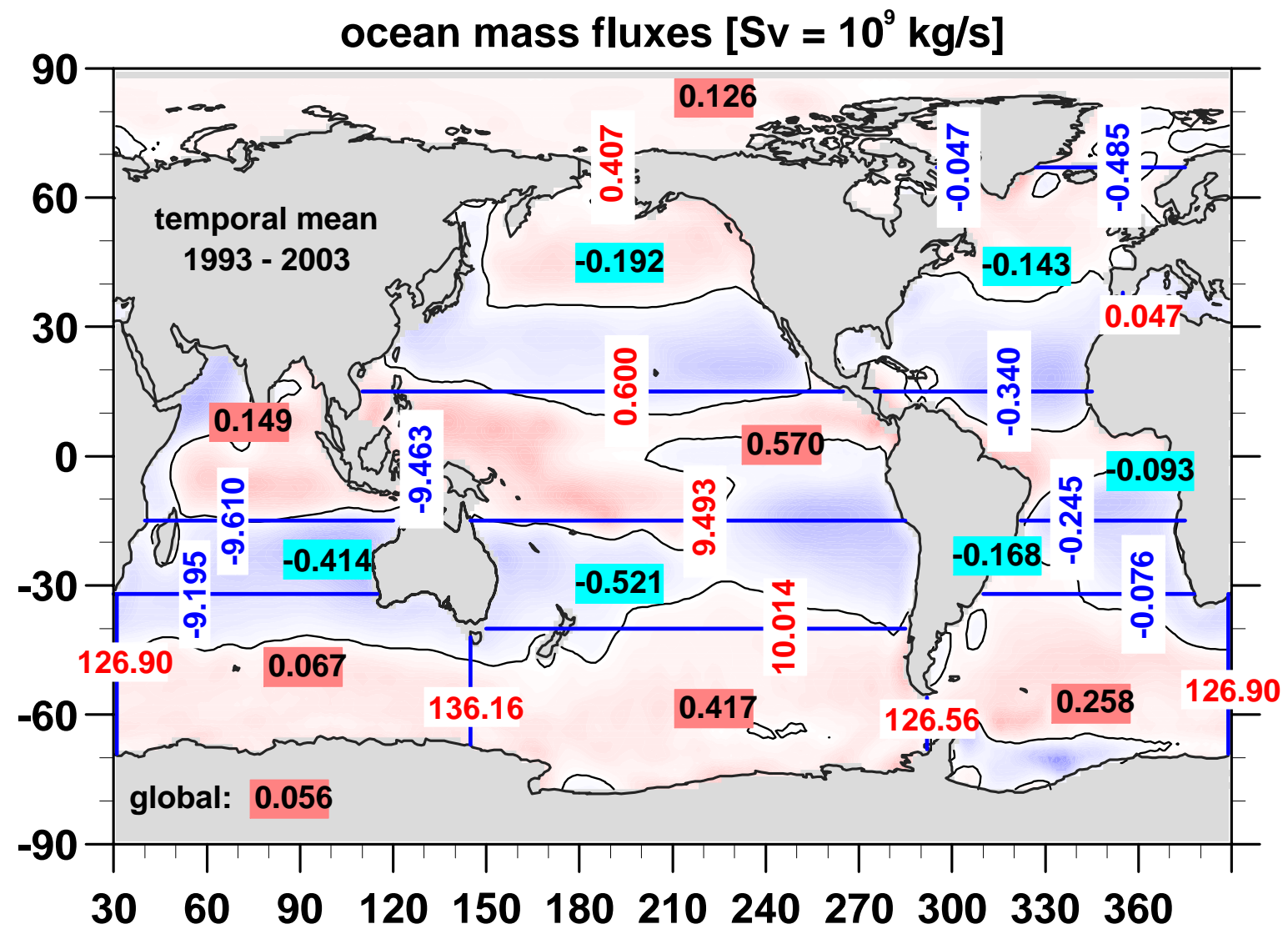

Figure 11: Temporal mean mass balance of the ocean. Horizontal transports are given on a white background (red: eastward and northward respectively, blue: southward). The transports through the area surfaces are given on a red background for into the ocean and on blue for out of the ocean. The overall background shading regives the mean surface freshwater flux (Fig.5a). The balances of the single ocean basins are summarized in Tab.1 